\title{
EDUCAÇÃO AMBIENTAL CRÍTICA PARA A CONVIVÊNCIA COM O SEMIÁRIDO: A FORMAÇÃO CONTINUADA DE DOCENTES NO CARIRI PARAIBANO
}

Myller Gomes Machado ${ }^{1}$

Francisco José Pegado Abílio²

Resumo: O presente estudo objetivou desvelar os saberes teórico-metodológicos, para uma prática crítica-reflexiva, a partir da formação continuada em Educação Ambiental (EA) Crítica na perspectiva da convivência com o Semiárido. A pesquisa utilizou da abordagem qualitativa com os pressupostos da pesquisa-ação críticocolaborativa. Os resultados demonstraram que as práticas docentes acerca da EA ocorriam inicialmente em dimensões conservacionistas e/ou pragmáticas e que 0 conhecimento do Semiárido se dava com base no "Paradigma da Seca". Já após a formação se consolidaram compreensões emancipatórias e compatíveis com os pressupostos da EA Crítica, da convivência com o Semiárido e da Racionalidade Prática e Crítica.

Palavras-chave: Educação Ambiental Crítica; Bioma Caatinga; Educação Contextualizada; Formação Continuada de Professores.

Abstract: The present study aimed to unveil the theoretical-methodological knowledge, for a critical-reflexive practice, based on the continued formation in Critical Environmental Education (EE) in the perspective of living with the SemiArid. The research used the qualitative approach with the assumptions of criticalcollaborative action research. The results showed that teaching practices about EE occurred initially in conservationist and/or pragmatic dimensions and that the knowledge of the Semiarid was based on the "Paradigm of Drought". After the training, emancipatory understandings were consolidated and compatible with the assumptions of Critical EE, coexistence with the Semiarid and Practical and Critical Rationality.

Keywords: Critical Environmental Education; Caatinga Biome; Contextualized Education: Continuing Teacher Education.

1 Serviço Social da Indústria - PB; Universidade Federal do Rio Grande do Norte - Campus Currais Novos. E-mail: myller-20@hotmail.com Link para o Lattes: http://lattes.cnpq.br/2383023695522446

2 Universidade Federal da Paraíba - Campus João Pessoa. E-mail: chicopegado@yahoo.com.br. Link para o Lattes: http://lattes.cnpq.br/3509554568530853 


\section{Introdução}

Atualmente, do ponto de vista socioeconômico, o Semiárido é um dos espaços do Brasil onde se manifesta mais intensamente o fosso que distância a base econômica do crescimento demográfico, uma vez que a migração para outras regiões do país se relaciona diretamente com a economia. Essa ocorre, a maioria das vezes, de atividades tradicionais de produtividade às industriais e agroindustriais. Para a maioria da população, o tipo de economia é vulnerável ao fenômeno das estiagens (MACAMBIRA, 2006). Qualquer desequilíbrio na distribuição das chuvas, que não possibilite a criação de animais e a produção agrícola, cria o caos na economia locorregional.

As políticas públicas para o Semiárido nordestino, como afirma Galindo (2008), foram pautadas por estratégias de combate à seca, sendo o principal fator que determinou o subdesenvolvimento da região. Isso é bem claro por trás das ações do Departamento Nacional de Obras Contra as Secas (DNOCS) com a ideia de combater o ambiente "inóspito" do Semiárido, que nesse seria inadequado o trabalho rural e, para nele viver, seria necessário intervir e modificá-lo (PONTES, 2011).

Sobre o bioma dominante, a Caatinga é o que abrange maior área dentro do Semiárido brasileiro, correspondendo a 63\% da área (ABÍLIO et al., 2010), estende-se diferentemente pelos estados de Sergipe, Alagoas, Bahia, Ceará, Paraíba, Pernambuco, Piauí, Rio Grande do Norte, parte do Maranhão e a região norte de Minas Gerais. Sendo esse bioma o único exclusivamente brasileiro e que cobre aproximadamente $10 \%$ do território nacional. Todavia, $62 \%$ das áreas susceptíveis à desertificação estão em zonas originalmente ocupadas por Caatinga (BRASIL, 2021).

Nesse sentido, percebendo a necessidade de modificações relacionadas às práticas políticas e socioambientais que ocorrem na região, se enfatiza a importância de outro tipo de prática educacional, a Educação Contextualizada (EC) tendo como enfoque a Convivência com o Semiárido brasileiro. Segundo Tavares (2009), a EC se baseia na realidade social dos sujeitos e possibilita contextualizar o processo de ensino e aprendizagem com a diversidade cultural de cada lugar, promovendo a produção do conhecimento apropriado a cada realidade.

A escola, tendo um propósito de mudança, se coloca em um lugar de destaque dentro da sociedade para a efetivação da EC, sendo um importante veículo de formação de conhecimento, ação enquanto sujeito social e assim espaço de busca para uma melhoria na qualidade de vida. E é nesse sentido que se enfatiza uma Educação Ambiental (EA) Crítica (LAYRARGUES; LIMA, 2014) e contínua que aborde diferentes aspectos, tais como: construções, desconstrução e reconstruções e ultrapassagens paradigmáticas de ideias, padrões e modos de entender e materializar o mundo.

Desse modo, a incorporação da questão ambiental no cotidiano das pessoas pode propiciar uma nova compreensão nas relações entre o ser 
humano, sociedade e natureza, promovendo uma reavaliação de valores e atitudes na convivência coletiva e individual, como também reforça a necessidade de ser e agir como cidadão na busca de soluções para problemas ambientais locais e nacionais que prejudicam a qualidade de vida.

\section{A formação continuada de docentes em EA Crítica}

A formação docente é um processo contínuo e precisa ser entendida como algo que faz parte dos diversos componentes relacionados à escola. Durante a prática pedagógica, aspectos relacionados à formação inicial vão sendo consolidados e maneiras de superar as lacunas deixadas por esse processo vão sendo encontradas pelo caminho. Uma dessas saídas é a preocupação com a formação continuada, entendendo que "além da formação inicial consistente, é preciso considerar um investimento educativo contínuo e sistemático para que o professor se desenvolva como profissional da educação" (BRASIL, 2000, p. 30).

Castellar (2017) enfatiza a importância de colocar o professor diante de um processo de discussão sobre as práticas pedagógicas que o façam compreender a importância de estar em estado de mobilização, que "a ação pedagógica, sendo significativa, contribui para formar cidadãos críticos ao mesmo tempo em que permite que o docente tome consciência do sentido em assumir uma vida intelectual' (CASTELLAR, 2017, p. 106).

No documento das Diretrizes Curriculares Nacionais para a Formação Inicial e Continuada de Professores (BRASIL, 2015, p. 4-7) são apontadas como princípios do processo formativo

as questões socioambientais, éticas, à diversidade étnicoracial, de gênero, sexual, religiosa, de faixa geracional e sociocultural como princípios de equidade; demonstrar consciência da diversidade, respeitando as diferenças de natureza ambiental-ecológica [...] e de classes sociais; realizar pesquisas que proporcionem conhecimento sobre os estudantes e sua realidade sociocultural, sobre processos de ensinar e de aprender, no meio ambiental-ecológico, entre outras problemáticas centrais da sociedade contemporânea.

Pode-se compreender, desta forma, que a dimensão ambiental se faz necessária à formação de qualquer indivíduo, como é disposto pela Política Nacional de EA (Lei 9795/99). Sendo significante a divulgação e apropriação da EA em dimensões críticas pelo corpo docente como prática educacional implícita em todas as suas ações educativas, seguindo conceitos que enfoquem a natureza como fonte de vida e relacione ambiente e justiça social, associando aos direitos humanos e saúde (BRASIL, 1999). Segundo o documento, "os professores em atividade devem receber formação complementar em suas áreas de atuação, com o propósito de atender 
adequadamente ao cumprimento dos princípios e objetivos da Política Nacional de EA" (BRASIL, 1999, p. 3).

Corroborando, as Diretrizes Curriculares Nacionais da EA (Resolução no 2, de 15 de junho de 2012) (DCNEA) enfatizam a necessidade da EA na formação inicial e continuada de professores em que:

Os órgãos dos sistemas de ensino devem articular-se entre si, com as universidades e demais instituições formadoras de profissionais da educação para que os cursos e programas de formação inicial e continuada de professores, gestores, coordenadores, especialistas e outros profissionais que atuam na Educação Básica e na Superior capacitem para o desenvolvimento didático-pedagógico da dimensão da EA na sua atuação escolar e acadêmica e deem condições concretas de formação continuada, para que se efetivem os princípios e se atinjam os objetivos da EA (BRASIL, 2012, p. 3).

Pensar a proposta da EA Crítica para o processo de formação continuada de docentes nos remete a perceber a realidade complexa e a necessidade de um novo tipo de educação que considere todas as dimensões do ser humano. Por exemplo, refletir sobre os conflitos socioambientais que em sua essência são gerados pelos aspectos econômicos, culturais ou das civilizações, provocando impactos no planeta, e, nesse contexto, a educação tem um papel fundamental de estruturar a vida individual e social da humanidade (NICOLESCU, 1999).

A formação continuada em EA Crítica ultrapassa a formação teórica cognitiva uma vez que "potencializa o ser humano a assumir um papel protagonista no fortalecimento de movimentos contra-hegemônicos" (FREIRE; FIGUEIREDO; GUIMARÃES, 2016, p. 121), na construção de novas relações sustentáveis. É uma formação que se realiza pela práxis na ação de intervir na realidade socioambiental, teorizando-a a partir de novos referenciais para a ação docente. Essa deve compreender uma formação abrangente que contemple um educador criativo, crítico, dialógico - freireanamente falando - e que traga a intencionalidade de colaborar com a partilha de novos meios de aprender na relação e na parceria (FREIRE; FIGUEIREDO; GUIMARÃES, 2016).

Em uma concepção crítica de formação continuada em EA, Guimarães (2013) menciona que o educador é agente da sociedade que atua no processo de transformações sociais e nessa se transforma, ou seja, o ensino é teoriaprática, é práxis. Ensino que se abre para a comunidade com seus problemas socioambientais. Aqui a compreensão e atuação sobre as relações de poder que permeiam e estruturam a sociedade são priorizados, significando uma educação política a qual nos faz perceber e ser os sujeitos que somos na história. 
A formação continuada em EA Crítica tem sua base no próprio ambiente, de entender os seus limites frente ao consumismo exacerbado do humano e que esses são diretamente proporcionais aos problemas sociopolíticos e econômicos. E nesse contexto, a educação é a essência para a (re)organização de novas formas de pensar e agir, em perspectivas de transformação, a partir do estabelecimento de um novo paradigma educacional, que também se solidifica nas relações sociais, uma vez que os processos educativos são cruciais no arranjo da sociedade.

Portanto, esta pesquisa objetivou desvelar os saberes teóricometodológicos, para uma prática crítica-reflexiva, a partir da formação continuada em EA Crítica na perspectiva da convivência com o Semiárido.

\section{Metodologia}

Este trabalho se caracterizou como uma pesquisa de abordagem qualitativa (OLIVEIRA, 2016), onde se utilizou os pressupostos teóricometodológicos da pesquisa-ação crítico-colaborativa (PIMENTA, 2005).

A pesquisa ocorreu no município de São José dos Cordeiros, que está no estado da Paraíba, especificamente na região ocidental do planalto da Borborema, sendo essa denominada Cariri em homenagem aos índios da Nação Cariri que iniciaram o povoamento nessa região (BEZERRA; RODRIGUEZ, 2000).

A formação continuada se deu através de vivências pedagógicas com os docentes das escolas públicas da cidade e foi realizada na Escola Estadual de Ensino Fundamental e Médio Bartolomeu Maracajá, em intervalos mensais (em um total de quatro atividades). Ocorrendo entre o período de julho a outubro de 2019.

A construção dos dados foi feita através dos questionários aplicados antes (pré) e após (pós) o término da formação e da observação participante realizada durante as vivências. As respostas dos docentes foram organizadas seguindo as categorias de Bardin (2011) a partir da análise de conteúdo do tipo Categorial.

Os quadros 1 e 2 se organizam em categorias, constituintes e subconstituintes, para essa última existem frequências que se dividem em duas: a "Absoluta" (FA), que expressa em números a quantidade de vezes que cada subconstituinte ocorre nas respostas dos professores, e a Relativa (FR), que representa a porcentagem de cada subconstituinte na relação com todas as frequências absolutas.

Vale salientar que no primeiro encontro os docentes assinaram o Termo de Consentimento Livre e Esclarecido (TCLE) autorizando a divulgação de respostas para fins científicos. A pesquisa também foi aprovada pelo Comitê de Ética de uma instituição federal. 


\section{Resultados e Discussão}

Participaram da pesquisa treze docentes com idades entre 28 e 56 anos. Desses, doze eram mulheres e um homem, todos são graduados, sendo que $77 \%$ em nível de licenciatura, e a formação superior da maioria é em Letras Português $(23,1 \%)$ e História $(23,1 \%)$.

Inicialmente, acerca do conceito e características do termo EA Crítica, dos que responderam, a subconstituinte mais mencionada no questionário préformação foi "Compreensão dos problemas socioambientais" com 11,4\%. Entretanto no pós-formação, as que tiveram maiores frequências foram "Transformação socioambiental" (11\%) e "Conhecer a complexidade dos processos" (11\%). Outras que também ficaram entre as mais citadas foram "Compreensão dos problemas socioambientais", "Qualidade de vida" e "Resolver problemas reais" (essas três subconstituintes com 9,1\%) (Quadro 1).

Primeiramente foi identificado um dado inquietante, embora já esperado, em que mais da metade dos professores $(53,8 \%)$ no pré-formação informou não conhecer o termo. Fato esse aceitável, uma vez que a EA Crítica é um tema novo e emergente, principalmente no nosso país.

Subconstituintes como "Preservar o meio ambiente" e "Conservar o meio ambiente" explicitadas no pré-formação podem direcionar para a dimensão paradigmática Cartesiana. Uma vez que não discutem e nem inter-relacionam a problemática ambiental com a complexidade dos fenômenos inerentes a mesma, ou seja, simplifica os processos e não contextualiza com as relações socioambientais e assim destoa das características, de fato, da EA Critica.

A EA Crítica vem como superação/ultrapassagem à EA conservadora, preservacionista, fragmentada e descontextualizada que, muitas vezes acabam por reproduzir dicotomias e reducionismos na ação ambiental, reforçando a simplificação da realidade e mantendo às injustas relações de poder. O caráter educativo hegemônico fica, em grande parte, subordinado a resolução de problemas ambientais, vistos com finalidades pragmáticas, ou seja, com fins em si mesmos (LAYRARGUES, 1999).

Contudo, após a realização da formação continuada, foi notório o aumento significativo no número de subconstiuintes e assim o surgimento de novas características sobre a EA Crítica nas respostas dos docentes, como também a mudança nas respostas e a consolidação de concepções críticas sobre a EA.

Uma das subconstituintes mais mencionadas foi "Conhecer a complexidade dos processos", e essa é uma das características importante, uma vez que uma das bases epistemológicas do surgimento da EA Crítica foi justamente à negação que os problemas ambientais são dissociados das práticas sociais. 
Quadro 1: Percepções (pré-formação) e Concepções (pós-formação) dos professores participantes da pesquisa sobre o conceito e características da EA Crítica.

\begin{tabular}{|c|c|c|c|c|c|c|}
\hline \multirow[b]{2}{*}{ Categoria } & \multirow[b]{2}{*}{ Constituintes } & \multirow[b]{2}{*}{ Subconstituintes } & \multicolumn{2}{|c|}{ Pré-formação } & \multicolumn{2}{|c|}{ Pós-formação } \\
\hline & & & FA & FR\% & FA & FR\% \\
\hline \multirow{25}{*}{$\begin{array}{c}\text { Educação } \\
\text { Ambiental } \\
\text { Crítica }\end{array}$} & \multirow{11}{*}{$\begin{array}{l}\text { Do Humano/ } \\
\text { Sociedade }\end{array}$} & Ter opinião formada & 1 & $5,8 \%$ & - & - \\
\hline & & $\begin{array}{c}\text { Saber direitos e } \\
\text { deveres }\end{array}$ & 1 & $5,8 \%$ & 3 & $5,5 \%$ \\
\hline & & $\begin{array}{l}\text { Compreensão dos } \\
\text { problemas } \\
\text { socioambientais }\end{array}$ & 2 & $11,4 \%$ & 5 & $9,1 \%$ \\
\hline & & $\begin{array}{l}\text { Transformação } \\
\text { socioambiental }\end{array}$ & - & - & 6 & $11 \%$ \\
\hline & & Qualidade de vida & - & - & 5 & $9,1 \%$ \\
\hline & & $\begin{array}{c}\text { Resolver problemas } \\
\text { reais }\end{array}$ & - & - & 5 & $9,1 \%$ \\
\hline & & $\begin{array}{l}\text { Formas seres } \\
\text { responsáveis }\end{array}$ & - & - & 3 & $5,5 \%$ \\
\hline & & $\begin{array}{c}\text { Seres } \\
\text { Socioambiental- } \\
\text { mente preocupados }\end{array}$ & - & - & 5 & $9,1 \%$ \\
\hline & & $\begin{array}{c}\text { Estimular a ação } \\
\text { coletiva }\end{array}$ & - & - & 1 & $1,8 \%$ \\
\hline & & $\begin{array}{l}\text { Além do conservar e } \\
\text { preservar }\end{array}$ & - & - & 1 & $1,8 \%$ \\
\hline & & $\begin{array}{c}\text { Questionar os modos } \\
\text { de consumo }\end{array}$ & - & - & 2 & $3,6 \%$ \\
\hline & \multirow[t]{2}{*}{ Da Conservação } & $\begin{array}{c}\text { Conservar a } \\
\text { natureza }\end{array}$ & 1 & $5,8 \%$ & - & - \\
\hline & & $\begin{array}{l}\text { Conservação } \\
\text { socioambiental }\end{array}$ & - & - & 2 & $3,6 \%$ \\
\hline & Da Preservação & $\begin{array}{c}\text { Preservar o Meio } \\
\text { Ambiente }\end{array}$ & 1 & $5,8 \%$ & 2 & $3,6 \%$ \\
\hline & \multirow{2}{*}{$\begin{array}{c}\mathrm{Da} \\
\text { Conscientização }\end{array}$} & Conscientizar & 1 & $5,8 \%$ & - & - \\
\hline & & $\begin{array}{c}\text { Valorizar o meio } \\
\text { ambiente }\end{array}$ & - & - & 1 & $1,8 \%$ \\
\hline & $\begin{array}{c}\text { Da } \\
\text { Sensibilização }\end{array}$ & Sensibilizar pessoas & - & - & 1 & $1,8 \%$ \\
\hline & \multirow{2}{*}{$\begin{array}{c}\mathrm{Da} \\
\text { Biodiversidade }\end{array}$} & Manutenção & - & - & 1 & $1,8 \%$ \\
\hline & & Sistema finito & & & 1 & $1,8 \%$ \\
\hline & \multirow{5}{*}{$\begin{array}{l}\text { Do Ensino- } \\
\text { Aprendizagem }\end{array}$} & $\begin{array}{c}\text { Perspectiva } \\
\text { Transdisciplinar }\end{array}$ & 1 & $5,8 \%$ & 2 & $3,6 \%$ \\
\hline & & $\begin{array}{c}\text { Ensinar sobre a crise } \\
\text { ambiental }\end{array}$ & - & - & 1 & $1,8 \%$ \\
\hline & & $\begin{array}{c}\text { Conhecer a } \\
\text { complexidade dos } \\
\text { processos }\end{array}$ & - & - & 6 & $11 \%$ \\
\hline & & $\begin{array}{l}\text { Aprender sobre o } \\
\text { meio ambiente }\end{array}$ & - & - & 1 & $1,8 \%$ \\
\hline & & $\begin{array}{c}\text { Entender a crise } \\
\text { educacional }\end{array}$ & - & - & 1 & $1,8 \%$ \\
\hline & Não responderam & - & 5 & $53,8 \%$ & - & - \\
\hline \multicolumn{3}{|c|}{ Total de frequências } & 13 & $100 \%$ & 55 & $100 \%$ \\
\hline
\end{tabular}

Revbea, São Paulo, V. 16, № 6: 216-235, 2021. 
Nesse sentido, outra subconstituinte explicitada e que se relaciona com uma dimensão importante para a EA Crítica foi "Transformação socioambiental". A ultrapassagem paradigmática tem como um dos seus objetivos o empoderamento do conhecimento para mudança social, de mudar posturas, dogmas, valores, tendo como horizonte a busca por mitigação das desigualdades sociais e promoção da justiça social. Refletindo sobre a subconstituinte, Loureiro (2004b) ressalta que um dos compromissos da EA Crítica é com a transformação societária, de promover ações coletivas condizentes com a emancipação.

Outras subconstituintes explicitadas e que, segundo Gushiken e Oliveira (2020), se caracterizam como importantes elementos da EA Crítica são: "Estimular a ação coletiva", "Resolver problemas reais" e "Perspectiva Transdisciplinar".

Sobre o conceito e características do termo "Semiárido", no préformação, as subconstituintes mais abordadas foram "Estiagem" (48\%), "Seco" $(24 \%)$ e "Sazonalidade de chuvas" (8\%). No pós-formação, as mais explicitadas foram "Seco" (22,4\%), "Altas temperaturas" $(20,7 \%)$ e "Poucas chuvas" $(10,4 \%)$.

As respostas do pré-formação evidenciando apenas características relacionadas à problemas para conviver com/na região corroboram com questões historicamente enraizadas no Semiárido, que são os estereótipos.

Após as reflexões durante as vivências, surgiram outras constituintes e subconstituintes, e que nessas estão conglomeradas elementos complexos de entender o Semiárido além dos fatores ambientais, mas relacionando com questões sociais, culturais e políticas. Esse fato pode ser exemplificado com as subconstituintes "Culturalidade" e "Musicalidade" representadas, respectivamente, nas citações a seguir:

"Hoje vejo o Semiárido de outro modo, vejo a cultura, a importância dos nossos artistas, das nossas festas" - Docente 11.

"O Semiárido é uma região com muita cultura, aqui mesmo na nossa cidade temos diversos cantores, sanfoneiros" - Docente 10.

Acerca das características do termo Educação Contextualizada (EC) para a Convivência com o Semiárido Paraibano, no questionário pré-formação, uma parte expressiva (33,3\%) dos docentes não respondeu. Dos que respondeu, as subconstituintes mais citadas foram "Voltada para o cotidiano" $(26,6 \%)$ e "Contextualizar a realidade discente" (20\%). Já no pós- formação, todos demonstraram conhecer o termo e as mais explicitadas foram "Praticar o Paradigma da Convivência" e "Uso de técnicas para conviver" (ambos com 
11,3\%) e "Empoderar do conhecimento para mudar a realidade" e "Voltada para o cotidiano" (ambos com 8,5\%) (Quadro 2).

Quadro 2: Percepções (pré-formação) e Concepções (pós-formação) dos professores participantes da pesquisa sobre o conceito de EC para a Convivência no Semiárido.

\begin{tabular}{|c|c|c|c|c|c|c|}
\hline \multirow[t]{2}{*}{ Categoria } & \multirow[t]{2}{*}{ Constituintes } & \multirow[t]{2}{*}{ Subconstituintes } & \multicolumn{2}{|c|}{$\begin{array}{c}\text { Pré- } \\
\text { formação }\end{array}$} & \multicolumn{2}{|c|}{$\begin{array}{c}\text { Pós- } \\
\text { formação }\end{array}$} \\
\hline & & & FA & FR\% & FA & FR\% \\
\hline \multirow{10}{*}{$\begin{array}{c}\text { Educação } \\
\text { Contextualiza- } \\
\text { da para a } \\
\text { Convivência } \\
\text { com/no } \\
\text { Semiárido }\end{array}$} & \multirow{8}{*}{$\begin{array}{l}\text { Do humano/ } \\
\text { sociedade }\end{array}$} & $\begin{array}{l}\text { Voltada para o } \\
\text { cotidiano }\end{array}$ & 4 & $26,6 \%$ & 3 & $8,5 \%$ \\
\hline & & $\begin{array}{c}\text { Evidenciar as } \\
\text { necessidades dos } \\
\text { sujeitos }\end{array}$ & - & - & 1 & $2,9 \%$ \\
\hline & & $\begin{array}{l}\text { Trabalho em } \\
\text { colaboração }\end{array}$ & - & - & 1 & $2,9 \%$ \\
\hline & & $\begin{array}{l}\text { Praticar o Paradigma } \\
\text { da Convivência }\end{array}$ & - & - & 4 & $11,3 \%$ \\
\hline & & $\begin{array}{l}\text { Coexistência com os } \\
\text { demais seres }\end{array}$ & - & - & 1 & $2,9 \%$ \\
\hline & & $\begin{array}{l}\text { Empoderar do } \\
\text { conhecimento para } \\
\text { mudar a realidade }\end{array}$ & - & - & 3 & $8,5 \%$ \\
\hline & & $\begin{array}{l}\text { Mitigar socialmente } \\
\text { as desigualdades }\end{array}$ & - & - & 1 & $2,9 \%$ \\
\hline & & $\begin{array}{l}\text { Mudar posturas e } \\
\text { valores }\end{array}$ & - & - & 1 & $2,9 \%$ \\
\hline & \multirow{4}{*}{ Da região } & Conhecer o clima & 1 & $6,7 \%$ & - & - \\
\hline & & $\begin{array}{l}\text { Demonstrar as } \\
\text { potencialidades }\end{array}$ & - & - & 1 & $2,9 \%$ \\
\hline \multirow{10}{*}{$\begin{array}{c}\text { Educação } \\
\text { Contextualiza- } \\
\text { da para a } \\
\text { Convivência } \\
\text { com/no } \\
\text { Semiárido }\end{array}$} & & $\begin{array}{c}\text { Conhecer a } \\
\text { Caatinga }\end{array}$ & - & - & 1 & $2,9 \%$ \\
\hline & & $\begin{array}{l}\text { Discutir sobre o } \\
\text { problema da seca }\end{array}$ & - & - & 1 & $2,9 \%$ \\
\hline & \multirow{4}{*}{$\begin{array}{l}\text { Do ensino e } \\
\text { aprendizagem }\end{array}$} & $\begin{array}{c}\text { Valorizar os } \\
\text { conhecimentos } \\
\text { prévios }\end{array}$ & 1 & $6,7 \%$ & - & - \\
\hline & & $\begin{array}{l}\text { Contextualizar a } \\
\text { realidade discente }\end{array}$ & 3 & $20 \%$ & - & - \\
\hline & & Estudar a região & - & - & 1 & $2,9 \%$ \\
\hline & & $\begin{array}{l}\text { Proporcionar uma } \\
\text { formação crítica }\end{array}$ & - & - & 1 & $2,9 \%$ \\
\hline & & Utilizar materiais & 1 & $6,7 \%$ & - & - \\
\hline & $\begin{array}{l}\text { Das novas } \\
\text { tecnologias }\end{array}$ & $\begin{array}{l}\text { Uso de técnicas para } \\
\text { conviver }\end{array}$ & - & - & 4 & $11,3 \%$ \\
\hline & & Uso de cisternas & - & - & 1 & $2,9 \%$ \\
\hline & $\begin{array}{c}\text { Não } \\
\text { responderam }\end{array}$ & - & 5 & $33,3 \%$ & - & - \\
\hline & Total de frequê & & 15 & $100 \%$ & 25 & $100 \%$ \\
\hline
\end{tabular}


Um dado interessante que ocorreu no pré-formação foi a subcontituinte "Contextualizar a realidade discente", demonstrando que as respostas de alguns docentes já se alinhavam com as características da EC para a Convivência com o Semiárido, e que foi notado com maior veemência durante as vivências.

Após a formação, surgiram outras categorias de suma importância para a reflexão sobre o tema é que são características basais do tema, como exemplos de "Praticar o Paradigma da Convivência", "Uso de técnicas para conviver" e "Empoderar do conhecimento para mudar a realidade". E sobre essas três subconstituintes, como também pelas vivências, nota-se que os docentes reconstruíram significações acerca da EC para a Convivência com o Semiárido, trazendo reflexões complexas que ultrapassagem a fragmentação do saber, característica do paradigma Cartesiano.

Assim, percebemos que a EC em processos de convivência com a região, como menciona Braga (2004, p. 35) consolida-se principalmente em três dimensões:

A do estar junto para, na liberdade da existência, construir identidades e compartilhar a vida; a do viver comum, que é mais do que estar junto, pois implica aceitar o outro ser vivo (humano e natureza) como legitimo outro, na sua 'existencialidade', identidade e subjetividade; e da contestação e da luta, da dialética da existência e da afirmação da diferença, em que buscamos o equilíbrio entre as forças opostas da vida. Educar para a convivência é trabalhar essas dimensões junto com os sujeitos do processo educativo.

Essas características de uma EC para a convivência com o Semiárido se assemelham as respostas dos docentes, principalmente após a pesquisa, de praticar o Paradigma da Convivência, buscando, através do empoderamento do conhecimento contextualizado para o cotidiano (na relação docente-discente e processo de ensino-aprendizagem) ultrapassar o Paradigma da Seca, que historicamente massificou que a única salvação para o Semiárido era a chuva/água.

Por último, buscamos saber sobre o conceito e/ou características do que seria um docente crítico-reflexivo, no pré-formação as subconstituintes que atingiram maiores frequências foram "Participação dos alunos" (15,7\%) e "Entender a Realidade", "Ensinar de forma crítica-reflexiva" e "Exercer o dialogo" (todas essas com 10,5\%). Já após as vivências, as mais citadas foram "Estimular a pensar", "Práxis crítica" e "Práxis" (todas com 12,3\%).

Um dado que refletimos foi acerca da quantidade de docentes que não responderam essa pergunta no questionário pré-formação $(31,5 \%)$. Diferentemente do pós-formação em que todos responderam. Ainda no préformação ocorreu à citação da subconstituinte "Ensinar de forma crítica- 
reflexiva", sendo essa generalista e similar a pergunta, o que pode evidenciar, inicialmente, conhecimento superficial acerca da temática.

Já no pós-formação aconteceu à menção de diferentes subconstituintes que se coadunam com as características de "Docente crítico-reflexivo", como são os casos de "Refletir acerca das questões sociais", "Estimular a pensar", "Luta por igualdade de direitos", "Formar cidadãos críticos", "Práxis" e "Práxis crítica". É relevante mencionar a importância das vivências, uma vez que foram nelas que discutimos tais características acerca do docente crítico e reflexivo.

Acerca das subconstituintes "Práxis" e "Práxis crítica". A primeira relaciona-se apenas a prática, ou seja, de refletir sobre a docência e para melhorar a mesma. Já a "Práxis crítica", além de refletir sobre a prática pedagógica, se consolida também na crítica docente sobre os modos de organizar as instituições, a sociedade e os próprios processos de ensinar e aprender, o que direciona para o currículo.

\section{Vivências pedagógicas realizadas em processos críticos-colaborativos}

A primeira vivência realizada foi "Semiárido e Bioma Caatinga: caracterização e aspectos gerais". Essa se iniciou com a apresentação de um vídeo denominado "Especial bioma Caatinga3" que enfatizava as principais características do bioma e do Semiárido, como também a capacidade de resistência e resiliência. Após a discussão inicial acerca do vídeo e buscando o aprofundamento na temática em questão, utilizamos da exposição do tema de modo dialogado. Assim discutimos conceitos e características da Caatinga e do Semiárido, refletindo também sobre termos como EA e EA Crítica.

$\mathrm{Na}$ parte final da atividade, foram realizados dois jogos com o intuito de revisar os conceitos e os contextos discutidos, principalmente, durante a aula expositica-dialógica. Os jogos denominados de "Jogo dos conceitos" e "Jogo da Caatinga" estavam interligados e buscaram refletir sobre as características de diferentes assuntos discutidos durante a atividade, principalmente dos elementos relacionados a Caatinga e Semiárido, com foco em questões como espécies endêmicas, geografia e vegetação da região.

Durante a realização dos jogos foi notória a participação dos docentes, conforme a reflexão de um desses.

"É interessante uma atividade dessa, de usar jogos para facilitar a aprendizagem concreta do aluno, e nem se gasta muito tempo para ser organizada pela gente. É tão boa que nem vimos a hora passar, quando isso ocorre é sinal que estamos fazendo algo prazeroso" - Docente 12.

\footnotetext{
https://www.youtube.com/watch?v=zmmBxpFqA5U. Acesso em: 05 jan. 2021.
}

${ }^{3}$ Vídeo sobre o bioma Caatinga produzido pelo programa Globo Rural da TV Globo. Disponível em: 
Foi nesse contexto que se configurou as vivências da formação em processos críticos-colaborativos, estimulando o protagonismo docente, sua participação ativa nas decisões escolares e que esse sujeito entenda-se como intelectual com grandes responsabilidades na formação discente e assim na construção da sociedade.

$\mathrm{Na}$ segunda vivência, intitulada "EA e EA Crítica: histórico, conceitos, princípios, tendências e perspectivas", buscamos estimular os docentes para a compreensão do conceito da EA e da EA Crítica como uma macrotendência dentro da EA e a importância das suas práticas nas dimensões educacionais, políticas e sociais, evidenciando também as inter-relações e a complexidade existente entre esses aspectos.

Sabíamos que a construção de uma EA em perspectivas críticas não seria fácil, uma vez que tais problemáticas (como o entendimento do mundo e suas relações de forma fragmentada) já tinham sido constatados inicialmente, principalmente no questionário pré-formação. Assim, compreender a EA Crítica e sua relação entre teoria e prática precisaria de uma ampla discussão sobre a fragmentação do conhecimento, refletindo, por exemplo, que o ser humano não pode se perceber como sujeito dominador sob os outros seres vivos, refletindo também acerca da necessidade de uma mudança paradigmática do consumismo, da organização econômica e educacional.

Nesse sentido, como estratégia metodológica, decidimos destacar inicialmente as discussões acerca do meio ambiente, com foco no quando e como se começou a evidenciar tais temas mundialmente e nacionalmente. Esse modo de enfatizar o tema foi importante para os docentes perceberem as origens das problemáticas ambientais e o seu agravamento com o passar dos anos.

Após a discussão sobre as origens dos problemas ambientais, começamos a refletir sobre a EA. Primeiramente mencionamos as características gerais da $E A$, na sequência buscamos explicitar as macrotendências e as suas diferentes perspectivas paradigmáticas, como também a importância da EA Crítica como tendência que ultrapassa 0 Paradigma Cartesiano e se consolida nos elementos do Paradigma Emergente.

Nesse contexto, começamos a problematizar junto aos docentes como ocorre a formação dos nossos paradigmas, porque pensamos o que pensamos e somos o que somos. Refletimos também como é que são formadas nossas ações políticas (por exemplo, o porquê que defendemos a perspectiva $\mathrm{X}, \mathrm{Y}$ ou $Z$ na tomada de decisões ou no direcionamentos dos governantes), ambientais (por exemplo, a razão que enfatizamos que é necessário conservar a natureza ou utilizar os seus recursos) e econômicas (por exemplo, o motivo que grupos de pessoas defendem que é necessário distribuir dinheiro igual para todos e outros grupos querem concentração de dinheiro para poucos seres humanos e assim desigualdades sociais). 
Para maximizarmos a compressão do todo, das partes e das complexidades dos fenômenos imbricados na EA Crítica, utilizamos a ferramenta didática denominada de "Zoom". Essa vai demonstrando, a cada nova imagem apresentada no projetor, as partes de algo maior, a qual começa com uma figura de uma pessoa segurando uma revista e segue até a imagem da Via Láctea. E a cada nova característica que surgia, modificava-se a percepção dos professores do que se tratava o todo.

Desse modo, foi importante o uso da ferramenta didática "Zoom" para os docentes entenderem a EA Crítica e assim as características que a torna como parte e todo de algo de grande complexidade socioambiental, política, econômica, social, entre outros. E que para nos apropriarmos epistemologicamente e ontologicamente da EA Crítica, é necessário despirmos de dogmas e ultrapassarmos paradigmas que nos aprisionam a verdades que não correspondem ao real ou que é apenas real para aquele sujeito.

Nesta perspectiva, como menciona Leff (2012) sobre a necessidade de uma reapropriação social da natureza, o que perpassa por uma transição paradigmática e da necessidade de ultrapassarmos a EA apenas conservacionista e pragmática e adentrarmos na Crítica, foi discutido junto com os docentes a música de título "Absurdo" de autoria de Vanessa da Mata. A atividade ocorreu em duplas e os professores escolheram uma estrofe da música e produziram um texto evidenciando a relação do trecho com as bases epistemológicas da EA Crítica.

Dentre os diversos trechos escolhidos e textos produzidos pelos docentes, destaque para "Autos destrutivos, falsas vítimas nocivas? Desmatam tudo e reclamam do tempo" com o texto:

"A escolha do trecho se deu devido à ação nociva do humano no meio ambiente, visando o lucro desenfreado, "sem consciência" do impacto que irá causar. Podemos aqui relacionar isso a visão da ciência que almejava poder reverter a situação a favor da natureza. Desmatava, produzia em massa e mais na frente conseguiria que a natureza se renovasse. Ledo engano, pois essa produção em massa ocasionou o aquecimento global, causando maléficas transformações ao meio. A humanidade se tornou a bomba atômica da natureza, seres autodestrutivos como retratada na música e ao mesmo tempo, vítimas dessa ação nociva e predatória" - Docentes 06 e 13.

A partir do escrito dos docentes 06 e 13, podemos perceber diversas características da EA Crítica que já foram desvelados anteriormente e que aqui se materializam nos discursos. Como são os casos de elementos relacionados ao capitalismo e consumismo desenfreado, da necessidade de ultrapassagem do Paradigma Cartesiano que anunciava a ciência como capaz de reverter todos os problemas ambientais, entretanto atualmente é consenso científico a 
não veracidade desses fatos. Como também de substituirmos a visão egocêntrica, de natureza como posse humana, para uma dimensão a qual o ser humano se configura como mais um ser inserido em uma conjuntura ambiental.

Assim é necessário problematizar a realidade do processo educacional de uma EA reprodutora de elementos de opressão, embasada em elementos descontextualizados e acríticos, e, como afirma Guimarães (2004), a educação, não apenas ambiental desenvolvida no Brasil, ainda é ligada a práticas conservadoras com seus alicerces no período ditatorial, quase sempre desvinculados da realidade e das condições experienciais do sujeito, ou ainda, como denunciava Freire (2014), uma educação bancária, cujos conteúdos são narrados, mas não contextualizados e nem problematizados.

Foi evidenciando essas reflexões que finalizamos essa atividade de grande importância na transição paradigmática docente, em que a reflexão da relação sociopolítica e educacional-ambiental em níveis nacionais e internacionais foi constituída por elementos reflexivos e críticos, o que corrobora diretamente na prática dos sujeitos envolvidos na pesquisa, tanto educacional como social.

A terceira vivência foi "Humano-Sociedade-Natureza: do reducionismo do combate à seca à EA Crítica contextualizada para a Convivência com o Semiárido" e teve como foco a compreensão das diferentes formas de discursos sobre o combate à seca no Semiárido brasileiro e a importância do conhecimento, com ênfase na relação aluno-docente-sociedade, para a mudança paradigmática evidenciando a educação contextualizada para a convivência no Semiárido.

Iniciamos a reflexão utilizando slides sobre a temática, enfatizando acerca do processo histórico de construção da seca e de seus desdobramentos para a região do Semiárido, da Caatinga, do Cariri paraibano, como também de modos de convivência com as áreas Semiáridas em nível local, nacional e global.

Sequencialmente discutimos sobre os dois Paradigmas do Semiárido. 0 primeiro deles, historicamente massificado, é do combate à seca, que caracteriza a região como local que, pela ausência de água, está com sua sociedade condenada a viver em condições péssimas de infraestrutura, alimentação, sanitárias, entre outros. Em que a agricultura é totalmente dependente das chuvas ou grandes obras hídricas, como açudes e barragens, favorecendo assim aos latifundiários que detêm a maioria dos territórios nessas regiões. O Paradigma da Seca também apolitiza e oprime os sujeitos e os deixam submissos ao clientelismo e assistencialismo absoleto.

Como afirma Silva, Araújo e Araújo (2018), o Semiárido Brasileiro há muito vem sendo retratado como local dos flagelados, de retirantes, de fome, seca e miséria. Essa é uma construção social que vive no imaginário descritivo dos territórios semiaridianos, que acompanha os sujeitos dessas regiões. 
Entretanto, é necessário envolver os docentes, enquanto pessoas que vivem nessa região, para uma reflexão crítica sobre os seus conhecimentos e como esses são formados, evidenciando a dimensão complexa da formação, o que desencadeia questionamentos sobre as "cegueiras" do conhecimento (erro e ilusão) produzido sobre o Semiárido que historicamente é mencionado, escrito e lido pela cultura dominante imposta pela indústria da seca.

Nesse contexto, dialogamos sobre o Paradigma da educação contextualizada para a convivência com o Semiárido, que se baseia na prática social dos sujeitos e possibilita contextualizar o processo de ensinoaprendizagem com a diversidade cultural de cada lugar. Promovendo a produção de conhecimentos apropriados a cada realidade, em que a escola se coloca em um lugar de destaque dentro da sociedade para a efetivação da EC para a convivência. Sendo um dos pilares desse paradigma a compreensão dos saberes usando a realidade de vida, com seus limites e potencialidades, construindo conhecimentos para a modificação dessa mesma realidade.

A reflexão para enxergamos novas realidades acerca da região foi muito importante, conforme relatado por um docente durante a vivência.

"Se pararmos para pensar direito, quase tudo aqui no Cariri é contado pelo lado dos que detêm o poder, seja por terras como antigamente, seja por dinheiro ou por esta política hoje. E o conhecimento é a base dessa mudança, ou seja, é necessário conhecer o nosso lugar e como esse se formou, com potenciais e problemas, para melhorá-lo. $E$ isso que aconteceu hoje comigo, perguntas simples, como por exemplo: Por que continuam usando carro-pipa se nunca resolve o problema a longo prazo? Eu sabia que não resolvia e que isso estava associado por coisas políticas, mas, como falei, hoje, nessa "aula", com esse conhecimento, posso dizer que aprendi a enxergar a luta pelo poder de nossa região de modo diferente" - Docente 09.

A partir da afirmação do professor, é necessário para além de questionar - Paradigma de combate a seca, ultrapassá-lo. Evidenciando o novo paradigma, esse com perspectivas de compreensões complexas, que favoreçam as mudanças de concepções, posturas, ações e visões da realidade, a partir da inter-relação e interdependência das situações ambientais, culturais, econômicas, religiosas e sociais. Uma vez que a convivência parte de duas premissas principais: a de conviver para se empoderar do conhecimento e assim melhorar a realidade e a de conviver usando técnicas para a melhoria da agricultura, pecuária, captação de água, dentre outros.

Nessa perspectiva, a EA Crítica contextualizada para a convivência proporciona aos docentes adquirir um conhecimento critico sobre as estruturas 
sociais básicas (economia, estado, trabalho, política). Esse Paradigma da convivência é essencial como elemento de transformação da sua própria prática, na formação de intelectuais e cidadãos críticos e reflexivos.

Esse foi o propósito da vivência acerca da EA Crítica contextualizada para a convivência com o Semiárido: de estimular a compreensão e a práxis crítica docente/humana como luta contínua em prol da libertação dos indivíduos; de proporcionar a superação de pessoas com vidas marcadas pela dor da desumanização, desconstruindo termos como, por exemplo, "coitados" promovidos pela opressão e pela dominação social de determinados grupos sob outros; de questionar as diferentes formas de opressão e exclusão no mundo neoliberal; de não tomar como verdade absoluta o que te falam, o que se ver na TV, se escuta no rádio ou o que se ler na internet; e de, a partir da consolidação da autonomia dos sujeitos que moram no Nordeste, Semiárido, Caatingas e Cariris; perceber que a política, educação, meio ambiente e emancipação ocorrem de modo dinâmico e interconectados, e que são cruciais para a melhoria da qualidade de vida de todos.

$\mathrm{Na}$ última atividade, intitulada "EA Crítica e formação continuada docente: dimensões críticas, reflexivas e emancipatórias", procuramos evidenciar os tipos de racionalidades que materializaram as formações continuadas na história da educação formal em nível nacional e, nesse sentido, entender sobre a importância de uma formação continuada e da prática docente e social a partir da racionalidade crítica.

Inicialmente, a partir de slides, refletimos sobre quais são os tipos de formações, após o término da graduação, que já foram e/ou são trabalhadas com os docentes, evidenciando assim termos como reciclagem, treinamento, aperfeiçoamento, capacitação e a que os pesquisadores enfatizam que abrange as características que devem ser praticadas, que é a formação continuada de docentes.

Essas formações estão relacionadas com o modo de pensar a ciência e os cientistas, com os paradigmas dominantes, o currículo, o que se aprende e as práticas sociais. O que perpassa principalmente com as várias formas de se considerar o professor em desenvolvimento e de seu papel social como modelo de comportamento, como transmissor de conhecimento, como técnico, mediador do processo de ensino aprendizagem ou criador de possibilidades para o aprender. Assim discutimos os três tipos de racionalidades existentes na ciência, os paradigmas a que essas estão interconectados e quais são as epistemologias relacionadas ao ensinar e a apreensão do saber.

A racionalidade Técnica surge com o próprio paradigma Cartesiano, fragmentando o humano do que o mesmo estuda e ensina, retira-se a política e ratifica que a função do professor se resume a transmitir os conhecimentos e os alunos devem absorver esses, sem reflexão. Já a racionalidade Prática se direciona para a necessidade da reflexão da práxis escolar, de superar a relação linear e mecânica entre conhecimento científico e prática de sala de aula. Valorizando assim a prática na formação dos profissionais que possibilita

revista brasileira educação ambiental 
encontrar respostas para situações reais de incerteza e indefinição em sala de aula.

Ainda nessa perspectiva, refletimos acerca da existência de incongruências na racionalidade Prática e qual(is) motivo(s) da mesma não ser considerada Crítica. Nas diversas respostas durante a discussão, a que mais se aproximou da que os cientistas mencionam foi:

\begin{abstract}
"Até agora na apresentação e discussão, eu só vi coisas de dentro da escola, de refletir sobre a nossa docência, de melhorar os modos de ensino, a minha prática em sala de aula, mas e o resto? E a sociedade? Eu mudaria algo mudando apenas o jeito que ensino? Dificilmente" - Docente 06.
\end{abstract}

Assim, como explicitado pelo docente 06, a racionalidade Crítica evidencia características relacionadas ao empoderamento do conhecimento por parte do docente e, desse modo, perceber o mundo em suas complexidades, ou seja, que reflita sobre a prática escolar e as relações de poder existentes nela para assim estimular e criar possibilidades para a formação de estudantes capazes de solucionar os problemas reais da sociedade, de assumir riscos e para lutar no interior das contínuas relações de poder que levam a injustiças e desigualdades, tendo como propósito a transformação social.

Durante os diálogos na vivência sobre as características de um professor crítico-reflexivo, apresentamos para a discussão questionamentos como: É importante os alunos aprenderem o que eu ensino? Por qual motivo ensino o que ensino? $O$ que ensino faz com que os alunos pensem nas desigualdades do mundo? Ensino o que eu gostaria e acho que seria o correto a se ensinado para os discentes? Por que não estou diretamente ligado e participativo nas decisões acerca do que é pra ser ensinado?

Após questionar, refletimos sobre as perguntas e, nesse contexto, para muitos docentes, os diálogos foram de extrema significância, como mostrado no exemplo da fala:

"Agora pode ter certeza que participarei mais e de modo bem mais atento das reuniões pedagógicas, principalmente quando tiver em pauta a escolha dos livros, alguma discussão do Projeto Político Pedagógico (PPP) da escola. Acho que tirei as vendas dos meus olhos que nem sei por quantos anos estavam neles" - Docente 06. 
paradigma Cartesiano. De questionar o currículo ainda materializado num sistema dominante que defende o interesse de um grupo também dominante que busca manter o sistema quo e assim o faz também por intermédio do sistema de ensino, do que é e como é ensinado, ou seja, de modo fragmentado, destituído da realidade, desvinculado das relações de classe e apolitizado.

Finalizamos a vivência e a formação evidenciando sobre a necessidade do empoderamento do conhecimento para a solução de problemas reais como um dos pilares de uma educação transformadora e emancipatória, características elementares da EA Crítica e contextualizada para a convivência com o Semiárido.

\section{Conclusões}

A partir do questionário pré-formação e de diálogos iniciais durante as vivências com os docentes, compreendemos que os discursos sobre a EA ocorriam em dimensões conservacionistas e/ou pragmáticas, uma vez que esses demonstravam uma racionalidade Técnica e fragmentada acerca das relações socioambientais que ocorriam na região.

Fato similar ocorria sobre as características do Semiárido mencionados pelos professores, baseada demasiadamente nas influências do paradigma da Seca nas percepções dos professores, sobretudo quando se enfatiza sobre as situações-problemas que ocorriam na região. O direcionamento para melhorias perpassava apenas pelas chuvas, o que denotava uma visão simplificada e fragmentada da região, evidenciando o distanciamento de uma compreensão multifatorial baseada nas dimensões sociais, ambientais, culturais, econômicas e políticas que consolidam o Semiárido.

Todavia, com as reflexões constantes realizadas durante a pesquisa entre os envolvidos e atos de natureza crítica, se estimulou o empoderamento dos docentes e a legitimação de práticas pedagógicas emancipatórias, compatíveis com os pressupostos teóricos da EA Crítica e da Educação contextualizada para a convivência com o Semiárido. Esse quadro possibilitou um novo contexto/parâmetro que pode estimular o redimensionamento das condições materiais que sustentam o paradigma Cartesiano.

Assim, a pesquisa realizada durante a formação possibilitou a emersão da curiosidade docente pelo "novo", da nova dimensão da EA e de compreender, enquanto docente crítico e reflexivo, uma nova perspectiva da conjuntura escolar, do currículo e das suas relações de poder. Elementos esses situados em uma racionalidade Crítica que foi buscada nessa formação.

Agradecimentos: Ao Programa de Pós-Graduação em Educação da Universidade Federal da Paraíba e a CAPES pelo apoio financeiro à pesquisa, por tornar possível o doutoramento do primeiro autor desse artigo. 


\section{Referências}

ABÍLIO, F. J. P. et al. Bioma Caatinga: caracterização e aspectos gerais. In: ABÍLIO, F.P.A. (Org.) Bioma Caatinga: ecologia, biodiversidade, Educação Ambiental e práticas pedagógicas. João Pessoa: UFPB, 2010, p. 6-19.

BARDIN, Laurence. Análise de conteúdo. São Paulo: Edições 70, 2011.

BEZERRA, C. P.; RODRIGUEZ, J. L. Conhecendo o Cariri. Recife: Gráfica LICEU, 2000.

BRAGA, O. R. Educação e convivência com o Semi-árido: uma introdução aos fundamentos do trabalho político-educativo no Semi-árido brasileiro. In: KUSTER, Â.; MATTOS, B. (Org.). Educação no contexto do Semi-árido brasileiro. Fortaleza: Fundação Konrad Adenauer, 2004, p. 73-96.

BRASIL. Caatinga. Brasília: Ministério do Meio Ambiente, 2021. Disponível em: https://www.mma.gov.br/biomas/caatinga. Acesso em: 18 jan. 2021.

BRASIL. Diretrizes Curriculares Nacionais para a Educação Ambiental. Brasília: MEC/CNE, 2012.

BRASIL. Diretrizes Curriculares Nacionais para a Formação Inicial e Continuada dos Profissionais do Magistério da Educação Básica. Brasília: MEC, 2015.

BRASIL. Lei no 9795 de 27 de Abril de 1999. Dispõe sobre a Educação Ambiental, institui a Política Nacional de Educação Ambiental e dá outras providências.

Disponível

em: $<$ http://www.planalto.gov.br/ccivil 03/leis/19795.htm>. Acesso em: 31 mar. 2021.

BRASIL. Parâmetros Curriculares Nacionais: ensino médio. Secretaria de Educação Fundamental, Brasília, DF:MEC/SEF, 2000.

CASTELLAR, S. M. V. Geografia escolar e formação docente. In: CARVALHO, A. M. P. (Org.). Formação continuada de professores: uma releitura das áreas de conteúdo. 2 ed. São Paulo: Cengage, 2017, p. 101-124.

CONTRERAS, J. A autonomia de Professor. São Paulo: Cortez, 2002.

FREIRE, P. Pedagogia da Esperança: um reencontro com a pedagogia do oprimido. São Paulo: Paz e Terra, 2014.

FREIRE, L.; FIGUEIREDO, J.; GUIMARÃES, M. Papel dos professores/educadores ambientais e seus espaços de formação: qual é a Educação Ambiental que nos emancipa? Pesquisa em Educação Ambiental, v.11, n.2, pp. 117-125, 2016.

GUIMARÃES, M. Educação Ambiental Crítica. In: BRASIL. Identidades da Educação Ambiental brasileira. Ministério do Meio Ambiente. Diretoria de Educação Ambiental, Brasília, 2004, p. 25-34. 
GUIMARÃES, M. Por uma Educação Ambiental crítica na sociedade atual. Rev. Margens interdisciplinar, v. 7, n. 9, p. 11-22, 2013.

GUSHIKEN, Y.; OLIVEIRA, M. A. Educação Ambiental: entre a poética dos saberes populares e a emergência do conhecimento científico. Revista Brasileira De Educação Ambiental, v. 15, n. 5, p. 464-478, 2020.

LAYRARGUES, P. P. A resolução de problemas ambientais locais deve ser um tema-gerador ou a atividade-fim da Educação Ambiental? In: REIGOTA, M. (Org.). Verde Cotidiano: o meio ambiente em discussão. Rio de Janeiro: DP\&A Editora, 1999, p. 131-148.

LAYRARGUES, P. P.; LIMA G. F. C. As macrotendências político-pedagógicas da Educação Ambiental brasileira. Rev. Ambiente \& Sociedade. v. XVII, n. 1, p. 23-40, 2014.

LEFF, E. Saber Ambiental: sustentabilidade, racionalidade, complexidade, poder. 9. ed. Petrópolis, RJ: Vozes, 2012.

MACAMBIRA, D. M. O Semi-árido nordestino: estratégias para o desenvolvimento sustentável. Rev. Princípios, v. 83, p. 33-38, 2006.

NICOLESCU, B. Um novo tipo de conhecimento transdisciplinar. 1ํ. Encontro Catalisador do CETRANS - Escola do Futuro - USP. Itatiba - São Paulo, 1999.

OLIVEIRA, M. O. Como fazer pesquisa qualitativa. 7 ed. Petrópolis: Vozes, 2016.

PONTES, E. T. M. Transições paradigmáticas: do combate à seca à convivência com o Semiárido nordestino, o caso do programa Um Milhão de Cisternas no município de Afogados do Ingazeira-PE. Recife: Ed. Universitária da UFPE, 2011.

PIMENTA, S. G. Pesquisa-ação crítico-colaborativa: construindo seu significado a partir de experiências com a formação docente. Educação e Pesquisa, São Paulo, v. 31, n. 3, p. 521-539, 2005.

SILVA, L. P. C.; ARAÚJO, A. M. R. B.; ARAÚJO, A. E. A Educação Contextualizada para a convivência com o Semiárido Brasileiro como uma prática emancipadora. Revista Brasileira de Educação do Campo, v. 3, n. 1, p. 104-125, 2018. 